\title{
Nosocomial infection of COVID-19: A new challenge for healthcare professionals (Review)
}

\author{
QIU DU ${ }^{1 *}$, DINGDING ZHANG ${ }^{1-3^{*}}$, WEIMIN HU ${ }^{3 *}$, XUEFEI LI ${ }^{1}$, \\ QIONGRONG XIA ${ }^{1}$, TAISHEN WEN ${ }^{2}$ and HAIPING JIA ${ }^{3}$

\begin{abstract}
${ }^{1}$ Department of Immunology, College of Medical Technology, Chengdu University of Traditional Chinese Medicine, Chengdu, Sichuan 610072; ${ }^{2}$ Department of Medicine, Sichuan Provincial People's Hospital, School of Medicine, University of Electronic Science and Technology of China, Chengdu, Sichuan 611731;
\end{abstract} \\ ${ }^{3}$ Department of Microbiology and Immunology, North Sichuan Medical College, Nanchong, Sichuan 637100, P.R. China
}

Received October 30, 2020; Accepted January 19, 2021

DOI: $10.3892 /$ ijmm.2021.4864

\begin{abstract}
Nosocomial infections, also known as hospitalacquired infections, pose a serious challenge to healthcare professionals globally during the Coronavirus disease 2019 (COVID-19) pandemic. Nosocomial infection of COVID-19 directly impacts the quality of life of patients, as well as results in extra expenditure to hospitals. It has been shown that COVID-19 is more likely to transmit via close, unprotected contact with infected patients. Additionally, current preventative and containment measures tend to overlook asymptomatic individuals and superspreading events. Since the mode of transmission and real origin of COVID-19 in hospitals has not been fully elucidated yet, minimizing nosocomial infection in hospitals remains a difficult but urgent task for healthcare professionals. Healthcare professionals globally should form an alliance against nosocomial COVID-19 infections. The fight against COVID-19 may provide valuable lessons for the future prevention and control of nosocomial infections. The present review will discuss some of the key strategies to prevent and control hospital-based nosocomial COVID-19 infections.
\end{abstract}

\section{Contents}

1. Introduction

2. Transmission model of COVID-19

Correspondence to: Professor Dingding Zhang, Department of Medicine, Sichuan Provincial People's Hospital, School of Medicine, University of Electronic Science and Technology of China, 2006 Xiyuan Road, Gaoxin, Chengdu, Sichuan 611731, P.R. China E-mail: zhangdd25@126.com

*Contributed equally

Key words: nosocomial infection, healthcare professionals, prevention and control
3. Influencing factors associated with nosocomial infection

4. Preventative and containment strategies for nosocomial infection

5. Conclusion and future perspectives

\section{Introduction}

Since the inception of its outbreak, Coronavirus disease 2019 (COVID-19) has spread worldwide, claiming $>1,840,000$ lives (1). In addition to its global impact, COVID-19 has alarmed the healthcare community on the danger and harm of nosocomial infection. Nosocomial infection of COVID-19 has been discovered and reported in numerous healthcare facilities on a global scale.

A total of 48 COVID-19 cases, including 28 healthcare professionals (HCPs), 13 patients and 7 accompanying persons (ACPs) were associated with a nosocomial infection case in the pediatric dialysis unit of the University Hospital of Münster (Münster, Germany) (2). Among these cases, 4 COVID-19 cases had a 15-min face-to-face contact with healthcare workers without wearing personal protective equipment (PPE) and 7 other healthcare workers were infected while treating patients with COVID-19 at a distance of $<2$ meters without PPE (2). Carter et al (3) reported that 196 nosocomial COVID-19 cases (NC) out of 1,564 patients were from 11 hospitals in the UK and Italy. The mortality rate of NC patients was $27 \%$ and the median survival time in NC patients was 14 days (3). Wang et al (4) found that 57 cases were infected through hospital-associated transmission among 138 hospitalized patients with COVID-19, including 17 inpatients, 31 HCPs from general wards, 7 HCPs from the emergency department and 2 HCPs from the intensive care unit (ICU). Notably, an index case with abdominal symptoms caused 14 infections, including 10 HCPs with nosocomial COVID-19 infection and 4 hospitalized patients with an atypical abdominal symptom and fever (4). This index case with great capacity to cause infection was presumed to be a superspreader (4). Similar nosocomial infection cases were also found in France $(5,6)$, Canada (7), China (8) and South Korea (9) (Table I). Hence, it is urgent to determine the cause of these nosocomial infection cases. 


\section{Transmission model of COVID-19}

Nosocomial infections of COVID-19 include exogenous and endogenous infection, and pose a great threat to inpatients, HCPs and ACPs. Exogenous infection, also known as cross infection, is caused by pathogens that directly come from the environment through the HCP's hands or contaminated objects (10). In endogenous infection, patients, especially those who are immunocompromised, are infected by the normal flora from patients or the pathogens from hospital (10). It is hence essential to revisit the modes of transmission of COVID-19.

Source of infection. It is well understood that confirmed patients with COVID-19 are the main sources of infection in human-to-human transmission of COVID-19. Asymptomatic cases and superspreaders may also be potential sources of infection. Additionally, other patients with low immunity and infected patients with no or only mild symptoms may gather in hospital to spread the virus in the community through social interactions. Thus, nosocomial infection acts as a contributing factor of an outbreak $(11,12)$.

Asymptomatic individuals. AsymptomatiC patients are those without clinical manifestations but with positive nucleic acid results of Severe Acute Respiratory Syndrome Coronavirus 2 (SARS-CoV-2) or chest imaging (13). Asymptomatic individuals may not be ill enough to seek medical care, and this allows them to participate in a larger range of activities. Wang et al (14) stated that the transmissibility of asymptomatiC patients was fairly limited due to the lack of symptoms, including coughing and sneezing. Hence, they are unlikely to be the major driving force of transmission (14). However, Li et al (15) demonstrated that $86 \%$ of all patients with COVID-19 infection in China were asymptomatic individuals in the early stage, and they caused $79 \%$ of the documented COVID-19 cases with observed symptoms and the rapid spread throughout the country before the travel restrictions. These studies indicate that the discussion on COVID-19 transmissibility of asymptomatic individuals remains to be clarified.

Progress in COVID-19 containment has revealed that the proportion of asymptomatic individuals was higher than previous projections in Wuhan, China $(40-50 \%$ of all cases) (16). However, some studies have shown that this proportion may be as low as $10 \%(16,17)$. It has been reported that asymptomatic individuals can be divided into inapparent cases, which do not appear symptomatic for the incubation period and can even obtain positive results from laboratory tests, and presymptomatic cases (17). During the incubation period, presymptomatic individuals can transmit COVID-19 even before onset of clinical symptoms (18). He et al (18) found that the highest infectiousness occurred before symptom onset, and $44 \%$ of secondary cases originated from presymptomatic cases. Kimball et al (19) reported that a rapid transmission of COVID-19 occurred in a skilled nursing facility in King County (WA, USA). About half of infected individuals were asymptomatic or presymptomatic on the day of nucleic acid testing, and they may therefore contribute to the transmission of COVID-19 (19).
Superspreaders. Individuals who have a greater than average capability of infecting more people are known as superspreaders (20). Medical experts have claimed that superspreaders may trigger a fresh outbreak (19). It is hence necessary to analyze the epidemic chain of transmission of COVID-19 originating from a superspreader considering the increased strain virulence, and the differences in hosts and co-infection with another pathogen should be taken into account (21). Additionally, asymptomatic and mild symptomatic individuals may be another type of infection source of superspreading events (SSEs) due to lack of awareness and containment measures (22). In addition, the combined effects of biology, behavior and environmental factors may lead to superspreading events (20).

During SARS and Middle East Respiratory Syndrome outbreaks, nosocomial transmission was associated with SSEs, and numerous patients, including HCPs and ACPs, were infected with those events (23). Additionally, hospitals are relatively closed environments with often dense populations and poor ventilation, and are therefore more likely to be a transmission site compared with an open environment (24). Moreover, unrecognized or misdiagnosed infection cases in 11 directly transmitted infections, including SARS, were shown to be the main reason of SSEs, followed by the mode of transmission, contact frequency and co-infection (25).

In addition to the aforementioned scenarios, SARS-CoV-2 was detected in some discharged patients, who may still be potential virus carriers (26). Furthermore, it was reported that reverse transcription PCR test results may not fully correlate with transmissibility (27). The World Health Organization (WHO) suggests that patients should be released from isolation $>10$ days after symptom onset and after $>3$ additional days without symptoms (28).

Transmission routes. COVID-19 primarily spreads via air droplets and direct contact, but SARS-CoV-2 RNA can also be found in fecal specimens and the virus may be spread via an excretory route (29). Although neonatal infections of COVID-19 have been observed, there is no direct evidence of vertical mother-to-child transmission (30). Fan et al (31) analyzed two confirmed expectant mothers, and SARS-CoV-2 was not detected in any of the products of conception and newborns. This analysis indicated that the risk of vertical transmission route of COVID-19 was relatively low (31).

Liu et al (32) reported that the trace of SARS-CoV-2 RNA was extremely high in small and non-ventilated mobile toilets in public areas of two hospitals in Wuhan (China), and relatively low in the isolation and ventilated rooms. Notably, some cases of HCP infection in China were associated with aerosol transmission in relatively closed environments, long-term exposures and high-concentration pathogen aerosol environments $(33,34)$. The size of droplets is variable due to the force and pressure at emission, evaporation and environment influence; droplets (5-10 $\mu \mathrm{m}$ in diameter) remain in the air for a short time and settle within $1 \mathrm{~m}$ of the source, while aerosols $(\leq 5 \mu \mathrm{m})$ disseminate in the air over long distances $(35,36)$. A large droplet can become an aerosol in less than a second (35). van Doremalen et al (37) reported that SARS-CoV-2 is viable and infectious in aerosols for $3 \mathrm{~h}$. It has been shown that the virus can still be detected at a distance of $4 \mathrm{~m}$ from patients (38). 
Table I. Some nosocomial infection events of COVID-19.

\begin{tabular}{|c|c|c|c|c|c|c|}
\hline First author, year & Site & $\begin{array}{l}\text { Number of } \\
\text { infections }\end{array}$ & $\begin{array}{l}\text { Reported } \\
\text { timeline } \\
(2020)\end{array}$ & Events & $\begin{array}{c}\text { Patient } \\
\text { outcomes }\end{array}$ & Refs. \\
\hline $\begin{array}{l}\text { Schwierzeck et al, } \\
2020\end{array}$ & $\begin{array}{l}\text { Münster, } \\
\text { Germany }\end{array}$ & 48 & N/A & $\begin{array}{l}48 \text { cases including } \\
28 \text { HCPs, } 13 \text { patients and } \\
7 \text { accompanying persons }\end{array}$ & N/A & (2) \\
\hline Carter et al, 2020 & $\begin{array}{l}11 \text { hospitals in } \\
\text { UK and Italy }\end{array}$ & 196 & Feb 27-Apr 28 & $\begin{array}{l}27.0 \% \text { of patients with } \\
\text { nosocomial infection died, } \\
\text { and the median survival } \\
\text { time was } 14 \text { days }\end{array}$ & 53 died & (3) \\
\hline Wang et al, 2020 & $\begin{array}{l}\text { Zhongnan } \\
\text { Hospital, } \\
\text { Wuhan, China }\end{array}$ & 57 & Jan 1-28 & $\begin{array}{l}57 \text { people were confirmed } \\
\text { with COVID-19, including } \\
17 \text { inpatients and } 40 \mathrm{HCPs}\end{array}$ & N/A & (4) \\
\hline $\begin{array}{l}\text { Luong-Nguyen } \\
\text { et al, } 2020\end{array}$ & $\begin{array}{l}\text { Ile-de-France, } \\
\text { France }\end{array}$ & 15 & Mar 1-Apr 5 & $\begin{array}{l}15 \text { patients developed } \\
\text { nosocomial COVID-19 } \\
\text { infection (all of them had } \\
\text { co-morbidities) }\end{array}$ & $\begin{array}{l}2 \text { died, } \\
7 \text { hospitalized } \\
\text { and } 6 \text { discharged }\end{array}$ & (5) \\
\hline Vanhems, 2020 & $\begin{array}{l}\text { Lyon area, } \\
\text { France }\end{array}$ & 8 & Mar 10-13 & $\begin{array}{l}6 \text { cases were infected by } \\
2 \text { potential index cases, } \\
\text { including one } \mathrm{HCP}\end{array}$ & 2 died & (6) \\
\hline Elkrief et al, 2020 & Canada & 47 & Mar 3-May 23 & $\begin{array}{l}\text { The nosocomial infection } \\
\text { rate was } 19 \% \text { among } \\
252 \text { patients with cancer } \\
\text { and COVID-19 }\end{array}$ & $\begin{array}{l}22 \text { died, } \\
7 \text { hospitalized, } \\
3 \text { critically-ill and } \\
15 \text { outpatients }\end{array}$ & (7) \\
\hline Lai et al, 2020 & $\begin{array}{l}\text { Tongji Hospital, } \\
\text { Wuhan, China }\end{array}$ & 77 & Jan 1-Feb 9 & $\begin{array}{l}\text { The infection rate of HCPs } \\
\text { was } 1.1 \% ; 70 \text { HCPs were } \\
\text { infected in general clinics } \\
\text { or wards, } 7 \text { in fever clinics } \\
\text { or wards }\end{array}$ & $\mathrm{N} / \mathrm{A}$ & $(8)$ \\
\hline Ji et al, 2020 & South Korea & 119 & Feb 11-Mar 2 & $\begin{array}{l}\text { The first patient was } \\
\text { diagnosed with COVID-19 } \\
\text { two days after his } \\
\text { death; } 119 \text { patients were } \\
\text { confirmed with COVID-19 }\end{array}$ & 7 died & (9) \\
\hline Ji et al, 2020 & $\begin{array}{l}\text { Wuhan Mental } \\
\text { Health Center, } \\
\text { Wuhan, China }\end{array}$ & 80 & Jan 12 -Feb 8 & $\begin{array}{l}\sim 50 \text { patients and } 30 \text { HCPs } \\
\text { were confirmed with } \\
\text { COVID-19 }\end{array}$ & N/A & (9) \\
\hline
\end{tabular}

N/A, not applicable; COVID-19, Coronavirus disease 2019; HCP, healthcare professional.

If considering only the droplets and direct contact transmission of COVID-19, the recommended distance for HCPs from patients can be decreased to $1 \mathrm{~m} \mathrm{(35)}$.

Susceptible population. Patients of all ages are susceptible to COVID-19, especially elderly males (>55 years old) with underlying diseases, such as diabetes, hypertension and cardiovascular disease (39). Hospitalized patients in nursing homes or skilled care facilities with moderate to severe asthma, severe heart disease or low immunity (cancer, immunodeficiency or severe obesity) are all high-risk COVID-19 populations of endogenous infection (40).

Another noteworthy aspect of endogenous infection is healthcare-associated infections for critically ill patients caused by other pathogenic microorganisms. For example, ventilator-associated pneumonia (VAP) is the most common complication of mechanical ventilation (41). The estimated mortality of VAP is $13 \%$ (41). Zhou et al (42) reported that secondary infections occurred in 27/57 non-survivors of COVID-19, and VAP occurred in 10/32 patients who underwent invasive mechanical ventilation. He et al (43) reported that the nosocomial infection rate among patients with COVID-19 was $7.1 \%$; the most common infection was pneumonia, followed by bacteremia and urinary tract infection. The pathogens involved were Coagulase negative staphylococcus (27.9\%), Acinetobacter (20.9\%), Pseudomonas aeruginosa (14\%), Enterococcus faecium (11.6\%) and Klebsiella pneumoniae (9.3\%) (43). Under these circumstances, the death rate among patients with nosocomial infection was $15.4 \%$ (43). 


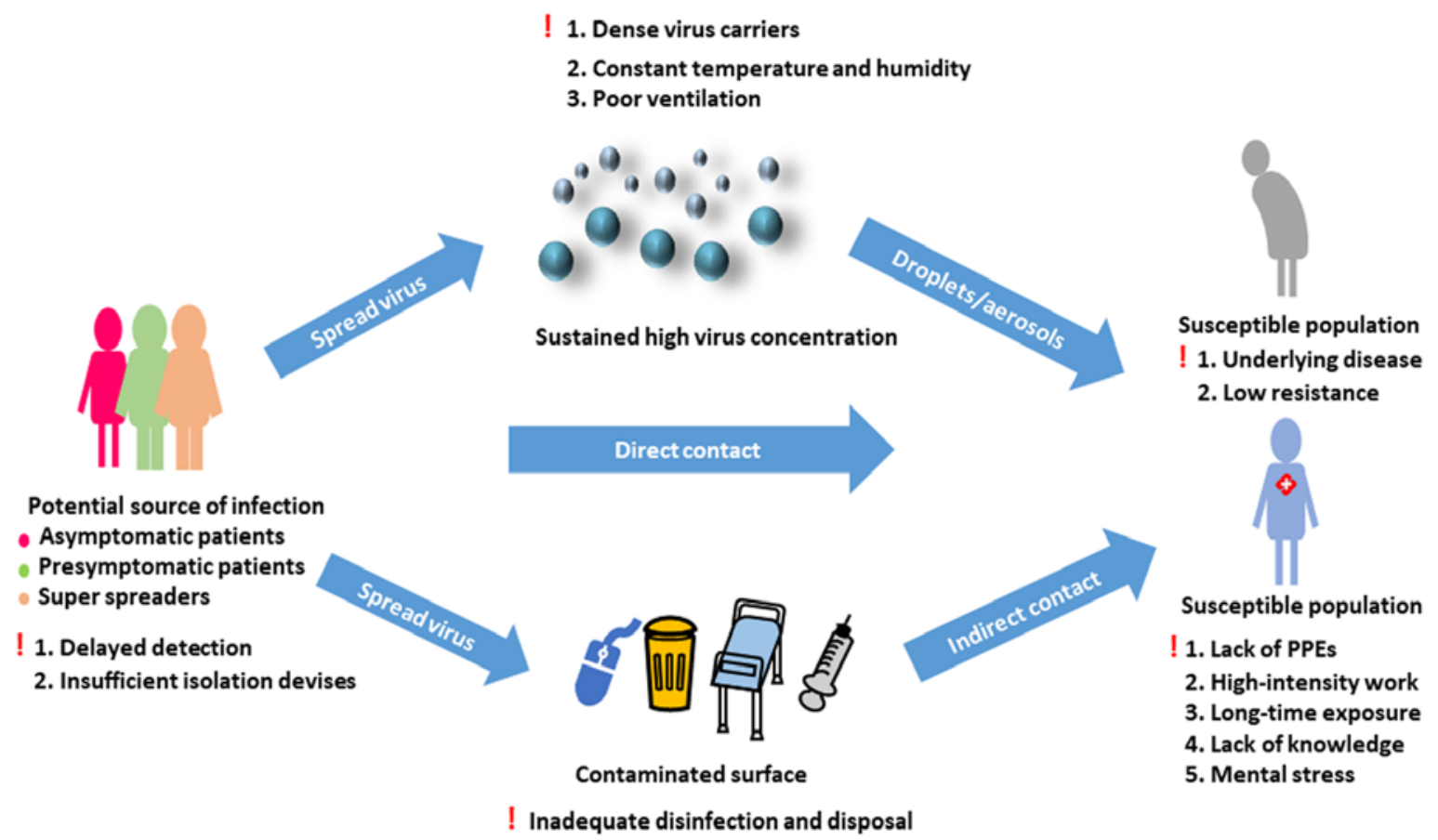

Figure 1. Transmission of Coronavirus disease 2019 in hospitals and factors contributing to the occurrence of nosocomial infection. Exclamation mark indicates the factors facilitating the occurrence of nosocomial infection. PPE, personal protective equipment.

\section{Influencing factors associated with nosocomial infection}

Lack of self-protection and containment measures may cause a cluster of cases in a hospital. During the early stages of the COVID-19 outbreak, the shortage of PPE and lack of awareness of the importance of personal protections were the main factors of new cases $(34,44)$. In addition, healthcare workers in non-communicable disease departments did not have sufficient knowledge on how to deal with potentially infectious diseases (9). This explains why non-communicable healthcare workers may be more likely to be infected (45). Additionally, in flu season, the transmissibility of the virus was almost always underestimated. Furthermore, numerous patients in long-term nursing facilities with little or no isolation equipment increase the risk of cross-infection (46). Lastly, ACPs may be exposed to the virus without personal protection; therefore, family visits may also increase the potential risk of COVID-19 exposure and infection (9).

The personal protection of HCPs is an important topic. Two studies concluded that HCP-infected COVID-19 cases were mostly due to lack of PPE at the very beginning of the pandemic $(33,34)$. A high-stress work environment may have further weakened the immunity of healthcare workers, and long-time exposure to patients may have rapidly increased their risk of infection (34). Additionally, these healthcare workers may not have received enough professional training in infectious disease control and prevention (33) (Fig. 1).

\section{Preventative and containment strategies for nosocomial infection}

Monitoring and controlling nosocomial infections are important routines in a hospital, as every hospital should implement effective programs according to its actual condition. This process typically involves four essential components: i) Conducting scientific surveillance and control measures; ii) Retaining professional epidemiologists; iii) Installing an infection control staff every 250 beds; and iv) A system for statistical analysis of nosocomial infection rates (47).

Triage of patients with COVID-19 for disease management. In the early stages of the COVID-19 outbreak, a large number of hospitals established 3- or 4-tiered patient triage strategies to reduce contact between the susceptible population and potential sources of infection $(48,49)$. At these hospitals, nurses prescreen patients at the entrance of the main lobby by checking the body temperature and scanning health QR codes. The three colors of QR codes (red, yellow and green) correspond to different risk levels (49). Patients would then be divided into different groups according to their body temperatures (Fig. 2).

Patients with a high body temperature would be transferred to a fever clinic through specific routes, accompanied by HCPs with sufficient protection, and epidemiologists would perform detailed COVID-19 checks (48). Other patients with no fever would be allowed for entrance into the general clinic, and specialists of all departments would prescreen for suspected cases according to the patients' body temperatures, epidemiological histories and QR codes (49). Patients with an epidemiological history, including a history of visiting the epidemic area within 14 days, contacting patients with symptoms suggestive of COVID-19 or from an epidemic area within 14 days, and epidemiological linkage with COVID-19, but with normal body temperatures would also receive the same treatments in different areas, while asked to stay in an isolation room for further treatment (48). The suspected patients' condition would be registered in detail and reported to the relevant departments (48). 


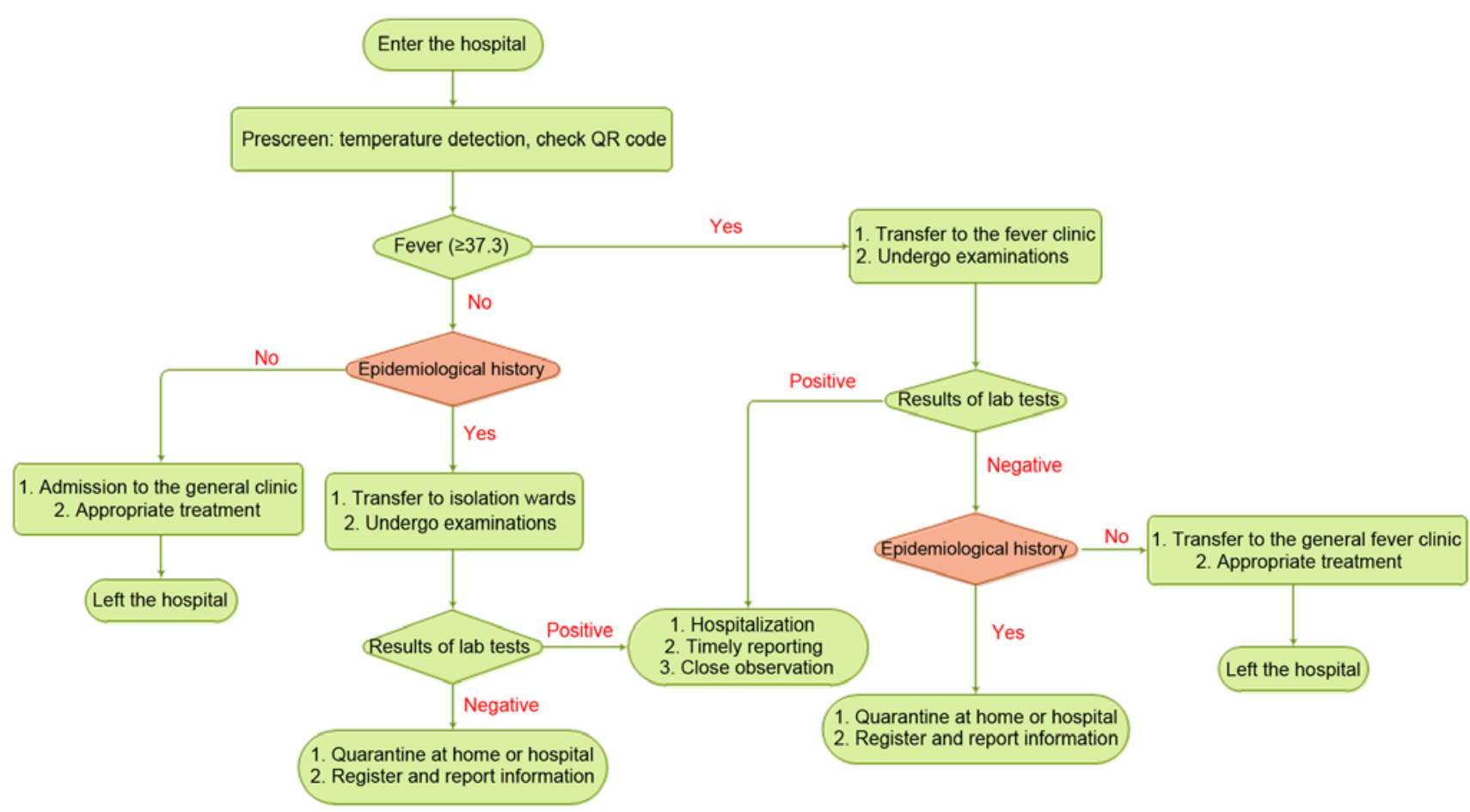

Figure 2. Triage strategies of patients in hospitals.

Reconciling the mismatch between hospital capacity and a large number of patients in a short-term period is a thought-provoking process. Currently, appropriate self-isolation is emphasized for most self-healing and suspected patients to reduce unnecessary visits to the hospital. There are a number of additional tools for reducing the consumption of unnecessary medical resources, such as mobile applications that can track geographic routes so that patients can self-report their own physical conditions and test results of COVID-19. Healthcare institutions can then find out where the outbreak centers are and take corresponding measures and allot materials by analyzing the data collected through these apps (50). Canadian scientists suggested that suspected patients with COVID-19 may be detected and monitored at home while equipped with instruments for measuring body temperature, blood pressure and heart rate (51). Additionally, HCPs can communicate safely with patients through remote monitoring systems (51). The effectiveness of home care depends on factors including professional guidance and management, and adequate measurements for nursing at home in cases of suitable conditions of the patients (52).

Furthermore, patients can be screened by telephone before they enter the hospital in order for HCPs to prepare for isolation before patients who need urgent care arrive to the hospital (53). In addition, internet hospitals in China provide medical consultation services for the public in order to alleviate the public's alarm, impart personal protection knowledge and correct inappropriate medical behaviors, thereby reducing unnecessary visits to hospitals (54).

Frontline HCPs have a distinctly higher risk of infection, especially those who re-use PPE or do not have adequate PPE (55). Htun et al (56) proposed a Staff Health Surveillance System to monitor employee travel experience, sick leave and detailed information, and record body temperature and N95 mask usage. These data provide important references for the management and protection for HCPs.

Specially redesigned wards in hospitals for patients with COVID-19. The Chinese Health Commission specifies that fever clinics are to be divided into special consulting rooms, specifically used for receiving patients with a high risk of COVID-19, and general consulting rooms, to receive patients with a low risk or a clear non-COVID cause of fever (48). These fever clinics, also known as wards, are located in a separate area and the entrance for patients is different from that of healthcare workers (49). The wards provide a convenient way of isolation from the outside and they are divided into two parts: One for isolating confirmed cases, which can host multiple patients, and the other for suspicious patients, where only one person is allowed per room (57). A buffer zone is located between the clean, semi-clean and contaminated areas to reduce staff exposure to infected cases, and HCPs take strict self-protection measures and go through disinfection before entering and leaving the contaminated area (58). Ventilation of the isolation ward is required to reach $60 \mathrm{l} / \mathrm{s}$, and the distances between beds are set to at least $1 \mathrm{~m} \mathrm{(59).} \mathrm{The} \mathrm{number} \mathrm{of} \mathrm{isolation} \mathrm{rooms} \mathrm{is}$ determined based on the epidemic condition and the number of patients received.

It is important to design and install appropriate isolation procedures, such as physical barriers or partitions to guide patients to different areas, curtains in the shared area to isolate patients, and installing and maintaining air treatment systems with directional, filtering equal capacity to maintain air circulation (60). Tang et al (61) suggested that the doors and windows of the isolation room should be kept closed to avoid reverse airflow.

High-risk treatment procedures that should be avoided. According to the transmission modes of COVID-19, 
treatment procedures that produce droplets and aerosols are high risk. Loeb et al (62) demonstrated that auxiliary intubation, suctioning before intubation and operating an oxygen mask were high-risk activities. Patients' secretions, saliva or blood may aerosolize to the environment while receiving treatment, especially in the stomatology department, with possible apparatus contamination (63). Hence, the risk of cross-infection increases through direct contact (63). Moreover, the virus can be detected in conjunctival swabs of patients with eye symptoms (64), indicating that patients who received slit lamp examination and direct ophthalmoscopy, as well as ophthalmologists, have a high risk of infection (65).

Incidentally, each medical department should suspend all unnecessary inspections to decrease the chance of transmission (65); only urgent surgeries should be arranged at the end of the day to reduce the risk of hospital infection $(63,66)$. Additionally, the number of health care assistants should be minimized, and patients who are at different risk levels of infection should be placed separately to reduce cross-infection (67).

The risk of nosocomial infection can be analyzed from two aspects: i) Daily risk of exposure, and ii) Total number of days of exposure. It has been shown that patients in the high daily risk department for a short time may have the same chance to be infected as patients in the low daily risk department for a long time (68). For each department, it is necessary to decrease the daily risk through various protective and disinfection measures, and shorten the treatment time of patients by reducing unnecessary treatment procedures (69).

Environmental surveillance and disinfection in wards and HCP offices should be enhanced. van Doremalen et al (37) has reported that the half-life of SARS-CoV-2 in aerosol is 1.1-1.2 $\mathrm{h}$ and has a longer viability period on stainless steel and plastic surfaces, with half-lives of 5.6 and $6.8 \mathrm{~h}$, respectively. Constant humidity and temperature for an extended period of time in the hospital may further prolong the survival period of the virus (32). Coronavirus is sensitive to ultraviolet light and heat, and most disinfectants (except for chlorhexidine) can effectively inactivate the virus $(70,71)$. Kampf et al (70) reported that using $62-71 \%$ ethanol, $0.5 \%$ hydrogen peroxide or $0.1 \%$ sodium hypochlorite can effectively inactivate human coronavirus within $1 \mathrm{~min}$; however, $0.05-0.2 \%$ benzalkonium chloride or $0.02 \%$ chlorhexidine and gluconate are less effective.

The virus can be widely distributed on the floor, computer mouse, trash cans and even bed handrails, and can be detected in $4 \mathrm{~m}$ of air surrounding a patient (38). Compared with contaminated areas, clean and semi-clean areas exhibited more sites where the virus was detected. Moreover, the contamination in isolation wards was even worse than that in ICUs $(58,72)$. These results indicate that HCPs may be exposed to a higher risk in isolation wards and semi-clean areas instead of contaminated areas. Therefore, it is important to enhance daily disinfection, particularly on key surfaces such as handle rails, switches and computer keyboards.

The wards of discharged patients should be fully disinfected. Sheets, curtains, ventilation, lighting and all surfaces should be carefully cleaned (73). For medical procedures that may generate aerosols, effective air isolation measures, including single rooms, negative pressure, frequent ventilation and powered air-purifying respirators, are required (74). Each department should formulate their own disinfection strategies, ensuring that all surfaces are cleaned and disinfected after daily operations $(63,65,75)$.

\section{Self-protection is important for HCPs}

$P P E$. Masks, goggles, protective clothing and good hand hygiene directly decreases the risk of nosocomial infection (76). Casanova et al (77) found that the coronavirus can survive $>24$ h on an N95 respirator, and at least for $4 \mathrm{~h}$ on other PPE. Therefore, it is important to train HCPs on how to wear and remove PPE correctly, and promptly dispose of used PPE. The correct order of wearing PPE is as follows: Hairnet, gown (with a back closure, may require two people), filter mask, goggles and finally two layers of gloves, with the inner layer covering up the wrist (75).

In order to improve the efficiency of protective devices, the usage of PPE is determined by the risk level of each patient, and the prevention measures are formulated according to the risk assessment of the epidemic (66). The WHO recommends using PPE for HCPs depending on the aerosol-generating procedures in different settings and the infection risk of patients. HCPs should wear medical masks and eye protection when screening patients without direct contact within $1 \mathrm{~m}$ (78). HCPs should use respirator N95 of FFP2 or FFP3 standard, gown, gloves, eye protection (goggles or face shield) and apron when collecting diagnostic respiratory samples in enclosed spaces or directly taking care of patients with COVID-19 (where aerosol-generating procedures are frequently performed) (78). When aerosol-generating procedures are not performed, the respirator can be replaced by a medical mask, and the apron is not required. When HCPs treat patients with symptoms suggestive of COVID-19, HCPs should use a medical mask, gown, gloves and eye protection (78). In addition, lab technicians who may handle the specimens from suspected or confirmed patients should use a medical mask, eye protection, gown and gloves, and should maintain a physical distance of at least $1 \mathrm{~m}(78)$.

Hand hygiene. Transmission through HCP hands in contact with contaminated surfaces also increases the risk of exogenous nosocomial infections (79). Hand cleaning and disinfection are the main steps that can stop pathogens from being transmitted from the patient to the HCP (80). HCPs in all departments need to thoroughly wash their hands before examination, after touching patients, after collecting patients' oral mucosa, blood and body fluids, and after touching equipment without sterilization (81). Pessoa-Silva et al (82) investigated the hand hygiene conditions of 149 newborn nursing staff, and the results revealed that the use of gloves did not completely protect HCP hands from bacterial contamination. Since numerous HCPs still believe that the purpose of using gloves is only for self-protection rather than protecting patients, hand washing compliance needs to be further reinforced. Hands should also be strictly sterilized before wearing gloves to avoid infection caused by broken gloves (83).

Education and training for HCPs and the public can decrease the risk of transmission. Patients in community or hospital isolation should strictly comply with medical guidance and wash their hands with water or soap for at least $20 \mathrm{sec}$ or with 
an alcohol-based hand sanitizer, avoid touching their eyes, cover their nose and mouth with tissues when coughing or sneezing, and disinfect objects and surfaces that are always touched (84). Patient education will increase awareness for hand hygiene (85). Based on a survey performed on a Chinese population, $98 \%$ of the participants would wear masks when they went outdoors; additionally, participants with a high socioeconomic status, especially females, were more educated about COVID-19 and complied better to PPE usage and hand hygiene guidance (86).

Sufficient knowledge and on-premises work experience may improve the ability of HCPs to better handle COVID-19, since incorrect attitudes and practices directly increase the risk of infection (87). In the early stages of the outbreak, the health administrative department of hospitals in China conducted professional training for medical workers through demonstrations, videos and other methods, including personal protection measures, medical waste disposal and emergency treatment agreements, and experts supervised the entire process of professional training. Before participating in the treatment of COVID-19, HCPs were subjected to medical examination and daily self-monitoring of respiratory symptoms (88). High-risk HCPs who were pregnant, $>55$ years of age or had a history of chronic diseases or acute fever were exempted from SARS-CoV-2-associated work (89).

Disposing medical wastes correctly to reduce avoidable transmission. During the COVID-19 outbreak, the demand of PPE and medical supplies increased dramatically. Wang et al (90) estimated that the daily demand for masks reached 900 million in China. There were too many medical wastes to be disposed of properly to reduce the potential risk of transmission among HCPs, patients and the public. Different types of waste should be collected in specific containers with labels to avoid accidental injury of cleaning staff and decrease the financial costs on waste disposal (91). Installing temporary disposal facilities and incinerators may relieve the pressure of a sharp increase in waste, and the risk of transportation may be influenced by the haul distance and location of facilities, which should be taken seriously according to economic costs and distance (92). Medical waste disposal procedures include collection and separation of medical wastes, transportation facility, proper waste disposal and staff protection and training (93). The WHO has given detailed advice on waste collection and destruction, as well as personnel training and protection (94). According to this advice, Chinese scientists gave guidance on the disinfection of wastes during the COVID-19 outbreak (95).

Logistic support measures are sustaining epidemic prevention efforts. With the surge in the number of infected cases, the demand of transportation vehicles and HCPs for transportation of patients and equipment for critically ill patients also increased sharply. Deployment and supply of personnel, equipment and drugs are of significance in treatment efficiency and containment of any epidemic. A fast and economical logistics model should be established according to the outbreak situation in various places. He and Liu (96) proposed that the sensitive-exposure-infection-recovery model may be considered as a basis of predicting the medical needs of various regions and formulating a material distribution plan. The 'Eagle-Eyed Observer' is a logistics support system that can monitor the physiological index of HCPs before and after entering the isolation ward, guide the HCPs to use PPE correctly and deal with used PPE, monitor the patient's situation and ward environment, and even organize medical supplies properly (97).

\section{Conclusion and future perspectives}

COVID-19 can be transmitted by direct contact with blood, body fluids, tissues of patients, droplets and surfaces contaminated by the virus. To date, nosocomial infections have occurred to varying degrees in different countries around the world. In hospitals, high population density, large numbers of susceptible people and the gathering of potential sources of infection are all contributing factors for nosocomial infections. A great amount of effort goes into nosocomial infection control of COVID-19. It is necessary to call for doctors' First Visit Responsibility in saving patients with COVID-19 and determine the handling of HCPs with direct or continuous exposure to infected patients.

Technology has played a crucial role in the prevention and control of COVID-19 in four ways. Firstly, artificial intelligence (AI)-driven robots or AI-assisted equipment have been very effective in fighting against the virus. It takes $1 \mathrm{~min}$ for a robot equipped with an AI-enabled fever-screening system to check the temperature of 200 people in an efficient and accurate manner; robot deliveries supported by cutting-edge technologies show promising potential for reducing direct exposure to the highly contagious virus (98). Secondly, digital technologies, such as big data and cloud computing, have been heavily utilized in containing and preventing outbreaks. There is an application prospect for the use of digital technologies in the evaluation of disease outbreaks. Thirdly, remote healthcare services backed by $5 \mathrm{G}$ communication technology are among the potential applications to ensure communication services for hospitals in different regions. Finally, remote visual medical treatment systems may aid in assisting front-line practices for healthcare workers to work remotely without direct exposure or continuous exposure to infected patients. This comprehensive network may serve an important role in minimizing the incidence of nosocomial infection.

Nosocomial infection constitutes an important part of an epidemic, especially in high-risk populations with insufficient prevention and control measures, including psychiatric hospitals and long-term care facilities. Improving the ability of detecting the mild or asymptomatic and presymptomatic individuals as early as possible is the key point in the current stage of the epidemic. Maintaining a safe distance, isolation measures, adequate material supplies and advanced telemedicine are important measures to control the epidemic. Limitations in the present review of the small-scale cases with COVID-19 infection are due to the finite number of nosocomial infection cases that have been reported. Further research on the association between nosocomial infection with subtypes of COVID-19 infection, such as the ordinary, severe or critical type, the days in hospital, ICU or relapse, and mutual infections during hospitalization, are deemed valuable for guiding clinical nursing and treatment. The present review indicates that once an epidemic occurs, a comprehensive 
analysis network may provide a powerful guideline for the next unknown virus or even the resurgence of COVID-19, and may pave the way to handle similar public health emergencies in the future.

\section{Acknowledgements}

Not applicable.

\section{Funding}

This study was supported by grants from the Department of Science and Technology of Sichuan Province (grant no. 20YFS0435), the Health Care of Sichuan Provincial cadres (grant no. 2020-227) and the Science \& Technology Bureau of Chengdu (grant nos. YF05-00198-SN and YF05-00060-SN).

\section{Availability of data and materials}

Not applicable.

\section{Authors' contributions}

QD and DZ contributed to the writing, reviewing and editing of the manuscript. QD and WH confirmed the authenticity of the data. QD, XL, QX, TW and HJ provided resources and created the figures. DZ and WH were involved in the conception of the study and provided supervision. All authors read and approved the final manuscript.

\section{Ethics approval and consent to participate}

Not applicable.

\section{Patient consent for publication}

Not applicable.

\section{Competing interests}

The authors declare that they have no competing interests.

\section{References}

1. World Health Organization (WHO): WHO coronavirus disease (COVID-19) dashboard. https://covid19.who.int/. Accessed January 19, 2021.

2. Schwierzeck V,König JC,KühnJ,Mellmann A,Correa-MartínezCL Omran H, Konrad M, Kaiser T and Kampmeier S: First reported nosocomial outbreak of severe acute respiratory syndrome coronavirus 2 (SARS-CoV-2) in a pediatric dialysis unit. Clin Infect Dis: ciaa491, Apr 27, 2020 (Epub ahead of print).

3. Carter B, Collins JT, Barlow-Pay F, Rickard F, Bruce E, Verduri A Quinn TJ, Mitchell E, Price A, Vilches-Moraga A, et al: Nosocomial COVID-19 infection: Examining the risk of mortality. The COPE-nosocomial study (COVID in Older PEople). J Hosp Infect 106: 376-384, 2020.

4. Wang D, Hu B, Hu C, Zhu F, Liu X, Zhang J, Wang B, Xiang H, Cheng Z, Xiong Y, et al: Clinical characteristics of 138 hospitalized patients with 2019 novel coronavirus-infected pneumonia in Wuhan, China. JAMA 323: 1061-1069, 2020.

5. Luong-Nguyen M, Hermand H, Abdalla S, Cabrit N, Hobeika C, Brouquet A, Goéré D and Sauvanet A: Nosocomial infection with SARS-Cov-2 within departments of digestive surgery. J Visc Surg 157: S13-S18, 2020.
6. Vanhems P: Fast nosocomial spread of SARS-CoV2 in a French geriatric unit lyon study group on covid-19 infection. Infect Control Hosp Epidemiol 41: 866-867, 2020.

7. Elkrief A, Desilets A, Papneja N, Cvetkovic L, Groleau C, Lakehal YA, Shbat L, Richard C, Malo J, Belkaid W, et al: High mortality among hospital-acquired COVID-19 infection in patients with cancer: A multicentre observational cohort study. Eur J Cancer 139: 181-187, 2020.

8. Lai X, Wang M, Qin C, Tan L, Ran L, Chen D, Zhang H, Shang K, Xia C, Wang S, et al: Coronavirus disease 2019 (COVID-2019) infection among health care workers and implications for prevention measures in a tertiary hospital in Wuhan, China. JAMA Netw Open 3: e209666, 2020.

9. Ji H, Liu L, Huang T and Zhu Y: Nosocomial infections in psychiatric hospitals during the COVID-19 outbreak. Eur J Psychiatry 34: 177-179, 2020.

10. Kerwat K, Graf J and Wulf H: Nosocomial infections. Anasthesiol Intensivmed Notfallmed Schmerzther 45: 30-31, 2010 (In German).

11. Fu C and Wang S: Nosocomial infection control in healthcare settings: Protection against emerging infectious diseases. Infect Dis Poverty 5: 30, 2016.

12. Cao GW, Zhang BX and Chen XP: Consideration on improving public health emergency management ability of current medical health system. Zhonghua Liu Xing Bing Xue Za Zhi 41: 1588-1594, 2020 (In Chinese).

13. Gao Z, Xu Y, Sun C, Wang X, Guo Y, Qiu S and Ma K: A systematic review of asymptomatic infections with COVID-19. J Microbiol Immunol Infect, May 15, 2020 (Epub ahead of print).

14. Wang Y, Kang H, Liu X and Tong Z: Asymptomatic cases with SARS-CoV-2 infection. J Med Virol 92: 1401-1403, 2020.

15. Li R, Pei S, Chen B, Song Y, Zhang T, Yang W and Shaman J: Substantial undocumented infection facilitates the rapid dissemination of novel coronavirus (SARS-CoV-2). Science 368: 489-493, 2020.

16. Qiu J: Covert coronavirus infections could be seeding new outbreaks. Nature, Mar 20, 2020 (Epub ahead of print).

17. Wu ZY: Contribution of asymptomatic and pre-symptomatic cases of COVID-19 in spreading virus and targeted control strategies. Zhonghua Liu Xing Bing Xue Za Zhi 41: 801-805, 2020 (In Chinese).

18. He X, Lau EHY, Wu P, Deng X, Wang J, Hao X, Lau YC, Wong JY, Guan Y, Tan X, et al: Temporal dynamics in viral shedding and transmissibility of COVID-19. Nat Med 26: 672-675, 2020.

19. Kimball A, Hatfield KM, Arons M, James A, Taylor J, Spicer K, Bardossy AC, Oakley LP, Tanwar S, Chisty Z, et al: Asymptomatic and presymptomatic SARS-CoV-2 infections in residents of a long-term care skilled nursing facility-king county, Washington, march 2020. MMWR Morb Mortal Wkly Rep 69: 377-381, 2020.

20. Cave E: COVID-19 super-spreaders: Definitional quandaries and implications. Asian Bioeth Rev: 1-8, May 16, 2020 (Epub ahead of print). doi: 10.1007/s41649-020-00118-2.

21. Stein RA: Super-Spreaders in infectious diseases. Int J Infect Dis 15: e510-e 513, 2011.

22. Al-Tawfiq JA and Rodriguez-Morales AJ: Super-spreading events and contribution to transmission of MERS, SARS, and SARS-CoV-2 (COVID-19). J Hosp Infect 105: 111-112, 2020.

23. Chowell G, Abdirizak F, Lee S, Lee J, Jung E, Nishiura H and Viboud C: Transmission characteristics of MERS and SARS in the healthcare setting: A comparative study. BMC Med 13: 210, 2015.

24. Frieden TR and Lee CT: Identifying and interrupting superspreading events-implications for control of severe acute respiratory syndrome coronavirus 2. Emerg Infect Dis 26: 1059-1066, 2020.

25. Lloyd-Smith JO, Schreiber SJ, Kopp PE and Getz WM: Superspreading and the effect of individual variation on disease emergence. Nature 438: 355-359, 2005.

26. Lan L, Xu D, Ye G, Xia C, Wang S, Li Y and Xu H: Positive RT-PCR test results in patients recovered from COVID-19. JAMA 323: 1502-1503, 2020.

27. Xiao AT, Tong YX and Zhang S: False negative of RT-PCR and prolonged nucleic acid conversion in COVID-19: Rather than recurrence. J Med Virol 92: 1755-1756, 2020.

28. World Health Organization (WHO): Home care for patients with suspected or confirmed COVID-19 and management of their contacts. https://www.who.int/publications/i/item/home-carefor-patients-with-suspected-novel-coronavirus-(ncov)-infectionpresenting-with-mild-symptoms-and-management-of-contacts. License: CC BY-NC-SA 3.0 IGO. Accessed August 12, 2020. 
29. Holshue ML, DeBolt C, Lindquist S, Lofy KH, Wiesman J, Bruce H, Spitters C, Ericson K, Wilkerson S, Tural A, et al: First case of 2019 novel coronavirus in the united states. N Engl J Med 382: 929-936, 2020.

30. Chen H, Guo J, Wang C, Luo F, Yu X, Zhang W, Li J, Zhao D, Xu D, Gong Q, et al: Clinical characteristics and intrauterine vertical transmission potential of COVID-19 infection in nine pregnan women: A retrospective review of medical records. Lancet 395: 809-815, 2020.

31. Fan C, Lei D, Fang C, Li C, Wang M, Liu Y, Bao Y, Sun Y, Huang J, Guo Y, et al: Perinatal transmission of COVID-19 associated SARS-CoV-2: Should we worry? Clin Infect Dis: ciaa226, Mar 17, 2020 (Epub ahead of print). doi: 10.1093/cid/ciaa226.

32. Liu Y, Ning Z, Chen Y, Guo M, Liu Y, Gali NK, Sun L, Duan Y, Cai J, Westerdahl D, et al: Aerodynamic analysis of SARS-CoV-2 in two Wuhan hospitals. Nature 582: 557-560, 2020.

33. Wang J, Zhou M and Liu F: Reasons for healthcare workers becoming infected with novel coronavirus disease 2019 (COVID-19) in China. J Hosp Infect 105: 100-101, 2020.

34. Sun H, Lu M, Chen S, Cheng Z, Xiong $Y$ and Wang $X$ : Nosocomial SARS-CoV-2 infection among nurses in wuhan at a single centre. J Infect 80: e41-e42, 2020.

35. Bahl P, Doolan C, de Silva C, Chughtai AA, Bourouiba L and MacIntyre CR: Airborne or droplet precautions for health workers treating COVID-19? J Infect Dis: jiaa189, Apr 26, 2020 (Epub ahead of print). doi: 10.1093/infdis/jiaa189.

36. World Health Organization (WHO): Transmission of SARS-CoV-2: Implications for infection prevention precautions https://www.who.int/publications/i/item/modes-of-transmissionof-virus-causing-covid-19-implications-for-ipc-precautionrecommendations. License: CC BY-NC-SA 3.0 IGO. Accessed July 9, 2020.

37. van Doremalen N, Bushmaker T, Morris DH, Holbrook MG, Gamble A, Williamson BN, Tamin A, Harcourt JL, Thornburg NJ, Gerber SI, et al: Aerosol and surface stability of SARS-CoV-2 as compared with SARS-CoV-1. N Engl J Med 382: 1564-1567, 2020

38. Guo ZD, Wang ZY, Zhang SF, Li X, Li L, Li C, Cui Y, Fu RB, Dong YZ, Chi XY, et al: Aerosol and surface distribution of severe acute respiratory syndrome coronavirus 2 in hospital wards, Wuhan, China, 2020. Emerg Infect Dis 26: 1583-1591, 2020.

39. Chen N, Zhou M, Dong X, Qu J, Gong F, Han Y, Qiu Y, Wang J, Liu Y, Wei Y, et al: Epidemiological and clinical characteristics of 99 cases of 2019 novel coronavirus pneumonia in Wuhan, China: A descriptive study. Lancet 395: 507-513, 2020.

40. Centers for Disease Control and Prevention (CDC): People at Increased Risk And Other People Who Need to Take Extra Precautions. https://www.cdc.gov/coronavirus/2019ncov/hcp/underlying-conditions.html. Updated January 4, 2021.

41. Boev C and Kiss E: Hospital-acquired infections: Current trends and prevention. Crit Care Nurs Clin North Am 29: 51-65, 2017.

42. Zhou F, Yu T, Du R, Fan G, Liu Y, Liu Z, Xiang J, Wang Y, Song B, Gu X, et al: Clinical course and risk factors for mortality of adult inpatients with COVID-19 in Wuhan, China: A retrospective cohort study. Lancet 395: 1054-1062, 2020.

43. He Y, Li W, Wang Z, Chen H, Tian L and Liu D: Nosocomial infection among patients with COVID-19: A retrospective data analysis of 918 cases from a single center in Wuhan, China. Infect Control Hosp Epidemiol 41: 982-983, 2020.

44. The L: COVID-19: Protecting health-care workers. Lancet 395: 922, 2020.

45. Al Maskari Z, Al Blushi A, Khamis F, Al Tai A, Al Salmi I, Al Harthi H, Al Saadi M, Al Mughairy A, Gutierrez R and Al Blushi Z: Characteristics of healthcare workers infected with COVID-19: A cross-sectional observational study. Int J Infect Dis 102: 32-36, 2021.

46. McMichael TM, Currie DW, Clark S, Pogosjans S, Kay M, Schwartz NG, Lewis J, Baer A, Kawakami V, Lukoff MD, et al: Epidemiology of covid-19 in a long-term care facility in king county, Washington. N Engl J Med 382: 2005-2011, 2020

47. Haley RW, Culver DH, White JW, Morgan WM, Emori TG, Munn VP and Hooton TM: The efficacy of infection surveillance and control programs in preventing nosocomial infections in US hospitals. Am J Epidemiol 121: 182-205, 1985.

48. Wang Q, Wang X and Lin H: The role of triage in the prevention and control of COVID-19. Infect Control Hosp Epidemiol 41 $772-776,2020$

49. Huang T, Guo Y, Li S, Zheng Y, Lei L, Zeng X, Zhong Q, Liu Y and Liu L: Application and effects of fever screening system in the prevention of nosocomial infection in the only designated hospital of coronavirus disease 2019 (COVID-19) in Shenzhen, China. Infect Control Hosp Epidemiol 41: 978-981, 2020.
50. McCullough PA, Eidt J, Rangaswami J, Lerma E, Tumlin J, Wheelan K, Katz N, Lepor NE, Vijay K, Soman S, et al: Urgent need for individual mobile phone and institutional reporting of at home, hospitalized, and intensive care unit cases of SARS-CoV-2 (COVID-19) infection. Rev Cardiovasc Med 21: 1-7, 2020.

51. Glauser W: Proposed protocol to keep COVID-19 out of hospitals. CMAJ 192: E264-E265, 2020.

52. Ramallo VJ, Rubio MM, Cuxart OE and Leoni ME: Usefulness of Hospital at home in nosocomial infections: Advantages and limitations. Rev Esp Quimioter 30 (Suppl 1): S61-S65, 2017.

53. Borrelli E, Sacconi R, Querques L, Zucchiatti I, Prascina F, Bandello $\mathrm{F}$ and Querques G: Taking the right measures to control COVID-19 in ophthalmology: The experience of a tertiary eye care referral center in Italy. Eye (Lond) 34: 1175-1176, 2020.

54. Gong K, Xu Z, Cai Z, Chen Y and Wang Z: Internet hospitals help prevent and control the epidemic of COVID-19 in china: Multicenter user profiling study. J Med Internet Res 22: e18908, 2020.

55. Iannone P, Castellini G, Coclite D, Napoletano A, Fauci AJ, Iacorossi L, D'Angelo D, Renzi C, La Torre G, Mastroianni CM and Gianola S: The need of health policy perspective to protect healthcare workers during COVID-19 pandemic. A GRADE rapid review on the N95 respirators effectiveness. PLoS One 15: e0234025, 2020

56. Htun HL, Lim DW, Kyaw WM, Loh WJ, Lee LT, Ang B and Chow A: Responding to the COVID-19 outbreak in Singapore: Staff protection and staff temperature and sickness surveillance systems. Clin Infect Dis 71: 1947-1952, 2020.

57. Agarwal A, Nagi N, Chatterjee P, Sarkar S, Mourya D, Sahay RR and Bhatia R: Guidance for building a dedicated health facility to contain the spread of the 2019 novel coronavirus outbreak. Indian J Med Res 151: 177-183, 2020.

58. Wang H, Mo P, Li G, Chen P, Liu J, Wang H, Wang F, Zhang Y and Zhao Q: Environmental virus surveillance in the isolation ward of COVID-19. J Hosp Infect 105: 373-374, 2020.

59. World Health Organization (WHO): Infection prevention and control during health care when novel coronavirus (nCoV) infection is suspected. https://www.who.int/publications/i/ item/10665-331495. License: CC BY-NC-SA 3.0 IGO. Accessed March 19, 2020

60. Centers for Disease Control and Prevention (CDC): Interim InfectionPreventionandControlRecommendationsforHealthcare Personnel During the Coronavirus Disease 2019 (COVID-19) Pandemic. https://www.cdc.gov/coronavirus/2019-ncov/infection-control/control-recommendations.html. Updated December $14,2020$.

61. Tang JW, Li Y, Eames I, Chan PK and Ridgway GL: Factors involved in the aerosol transmission of infection and control of ventilation in healthcare premises. J Hosp Infect 64: 100-114, 2006.

62. Loeb M, McGeer A, Henry B, Ofner M, Rose D, Hlywka T, Levie J, McQueen J, Smith S, Moss L, et al: SARS among critical care nurses, toronto. Emerg Infect Dis 10: 251-255, 2004.

63. Meng L, Hua F and Bian Z: Coronavirus disease 2019 (COVID-19): Emerging and future challenges for dental and oral medicine. J Dent Res 99: 481-487, 2020.

64. Wu P, Duan F, Luo C, Liu Q, Qu X, Liang L and Wu K: Characteristics of ocular findings of patients with coronavirus disease 2019 (COVID-19) in Hubei province, China. JAMA Ophthalmol 138: 575-578, 2020.

65. Lai THT, Tang EWH, Chau SKY, Fung KSC and Li KKW: Stepping up infection control measures in ophthalmology during the novel coronavirus outbreak: An experience from Hong Kong. Graefes Arch Clin Exp Ophthalmol 258: 1049-1055, 2020.

66. Liu Z, Zhang Y, Wang X, Zhang D, Diao D, Chandramohan K and Booth CM: Recommendations for surgery during the novel coronavirus (COVID-19) epidemic. Indian J Surg 11: 1-5, 2020.

67. Romano MR, Montericcio A, Montalbano C, Raimondi R, Allegrini D, Ricciardelli G, Angi M, Pagano L and Romano V: Facing COVID-19 in ophthalmology department. Curr Eye Res 45: 653-658, 2020.

68. Freeman J and McGowan JE Jr: Risk factors for nosocomial infection. J Infect Dis 138: 811-819, 1978.

69. Welt FGP, Shah PB, Aronow HD, Bortnick AE, Henry TD, Sherwood MW, Young MN, Davidson LJ, Kadavath S, Mahmud E, et al: Catheterization laboratory considerations during the coronavirus (COVID-19) pandemic: From ACC's interventional council and SCAI. J Am Coll Cardiol 75: 2372-2375, 2020 .

70. Kampf G, Todt D, Pfaender S and Steinmann E: Persistence of coronaviruses on inanimate surfaces and their inactivation with biocidal agents. J Hosp Infect 104: 246-251, 2020. 
71. National Health Commission of the People's Republic of China: Protocol on Prevention and Control of COVID-19 (Edition 6). http://en.nhc.gov.cn/2020-03/29/c_78467.htm. Updated March $29,2020$.

72. Lei H, Ye F, Liu X, Huang Z, Ling S, Jiang Z, Cheng J, Huang X, Wu Q, Wu S, et al: SARS-CoV-2 environmental contamination associated with persistently infected COVID-19 patients. Influenza Other Respir Viruses 14: 688-699, 2020.

73. Dancer SJ: Controlling hospital-acquired infection: Focus on the role of the environment and new technologies for decontamination. Clin Microbiol Rev 27: 665-690, 2014.

74. Wax RS and Christian MD: Practical recommendations for critical care and anesthesiology teams caring for novel coronavirus (2019-nCoV) patients. Can J Anaesth 67: 568-576, 2020.

75. Repici A, Maselli R, Colombo M, Gabbiadini R, Spadaccini M, Anderloni A, Carrara S, Fugazza A, Di Leo M, Galtieri PA, et al: Coronavirus (COVID-19) outbreak: What the department of endoscopy should know. Gastrointest Endosc 92: 192-197, 2020.

76. Cheng VC, Chan JF, To KK and Yuen KY: Clinical management and infection control of SARS: Lessons learned. Antiviral Res 100: 407-419, 2013.

77. Casanova L, Rutala WA, Weber DJ and Sobsey MD: Coronavirus survival on healthcare personal protective equipment. Infect Control Hosp Epidemiol 31: 560-561, 2010.

78. World Health Organization (WHO): Rational use of personal protective equipment for coronavirus disease (COVID-19) and considerations during severe shortages. https://www. who.int/publications/i/item/rational-use-of-personal-protectiveequipment-for-coronavirus-disease-(covid-19)-and-considerationsduring-severe-shortages. License: CC BY-NC-SA 3.0 IGO. Accessed December 23, 2020.

79. Vermeil T, Peters A, Kilpatrick C, Pires D, Allegranzi B and Pittet D: Hand hygiene in hospitals: Anatomy of a revolution. J Hosp Infect 101: 383-392, 2019.

80. Pittet D, Allegranzi B, Sax H, Dharan S, Pessoa-Silva CL, Donaldson L and Boyce JM; Evidence-Based model for hand transmission during patient care and the role of improved practices: Evidence-based model for hand transmission during patient care and the role of improved practices. Lancet Infect Dis 6: 641-652, 2006.

81. Peng X, Xu X, Li Y, Cheng L, Zhou X and Ren B: Transmission routes of 2019-nCoV and controls in dental practice. Int J Oral Sci 12: 9, 2020.

82. Pessoa-Silva CL, Dharan S, Hugonnet S, Touveneau S, Posfay-Barbe K, Pfister R and Pittet D: Dynamics of bacterial hand contamination during routine neonatal care. Infect Control Hosp Epidemiol 25: 192-197, 2004.

83. Petroudi D: Nosocomial infections and staff hygiene. J Infect Dev Ctries 3: 152-156, 2009.

84. Carlos WG, Dela Cruz CS, Cao B, Pasnick S and Jamil S: Novel Wuhan (2019-nCoV) coronavirus. Am J Respir Crit Care Med 201: P7-P8, 2020.

85. Evans CT, Hill JN, Guihan M, Chin A, Goldstein B Richardson MS, Anderson V, Risa K, Kellie S and Cameron KA: Implementing a patient education intervention about methicillin-resistant Staphylococcus aureus prevention and effect on knowledge and behavior in veterans with spinal cord injuries and disorders: A pilot randomized controlled trial. J Spinal Cord Med 37: 152-161, 2014.
86. Zhong BL, Luo W, Li HM, Zhang QQ, Liu XG, Li WT and Li Y: Knowledge, attitudes, and practices towards COVID-19 among Chinese residents during the rapid rise period of the COVID-19 outbreak: A quick online cross-sectional survey. Int J Biol Sci 16: $1745-1752,2020$

87. Zhang M, Zhou M, Tang F, Wang Y, Nie H, Zhang L and You G: Knowledge, attitude, and practice regarding COVID-19 among healthcare workers in Henan, China. J Hosp Infect 105: 183-187, 2020.

88. Wang H, Wang S and Yu K: COVID-19 infection epidemic: The medical management strategies in Heilongjiang province, China. Crit Care 24: 107, 2020.

89. Li T: Diagnosis and clinical management of severe acute respiratory syndrome coronavirus 2 (SARS-CoV-2) infection: An operational recommendation of peking union medical college hospital (V2.0). Emerg Microbes Infect 9: 582-585, 2020.

90. Wang MW, Zhou MY, Ji GH, Ye L, Cheng YR, Feng ZH and Chen J: Mask crisis during the COVID-19 outbreak. Eur Rev Med Pharmacol Sci 24: 3397-3399, 2020.

91. Ali M, Wang W, Chaudhry N and Geng Y: Hospital waste management in developing countries: A mini review. Waste Manag Res 35: 581-592, 2017.

92. Yu H, Sun X, Solvang WD and Zhao X: Reverse logistics network design for effective management of medical waste in epidemic outbreaks: Insights from the coronavirus disease 2019 (COVID-19) outbreak in Wuhan (China). Int J Environ Res Public Health 17: 1770, 2020.

93. Awodele O, Adewoye AA and Oparah AC: Assessment of medical waste management in seven hospitals in Lagos, Nigeria. BMC Public Health 16: 269, 2016.

94. World Health Organization (WHO): Infection Prevention and Control of Epidemic- and Pandemic-Prone Acute Respiratory Infections in Health Care. https://www.who.int/publications/i/ item/infection-prevention-and-control-of-epidemic-and-pandem ic-prone-acute-respiratory-infections-in-health-care. Accessed April 7, 2014

95. COVID-19 Emergency Response Key Places Protection and Disinfection Technology Team, Chinese Center for Disease Control and Prevention: Technical guideline for disinfection of wastewater and wastes of medical organizations during COVID-19 outbreak. Zhonghua Yu Fang Yi Xue Za Zhi 54: 353-356, 2020 (In Chinese).

96. He Y and Liu N: Methodology of emergency medical logistics for public health emergencies. Transp Res E Logist Transp Rev 79: 178-200, 2015.

97. Peng J, Ren N, Wang M and Zhang G: Practical experiences and suggestions for the 'eagle-eyed observer': A novel promising role for controlling nosocomial infection in the COVID-19 outbreak. J Hosp Infect 105: 106-107, 2020.

98. Ye Q, Zhou $\mathrm{J}$ and $\mathrm{Wu} \mathrm{H}$ : Using information technology to manage the COVID-19 Pandemic: Development of a technical framework based on practical experience in China. JMIR Med Inform 8: e19515, 2020.

This work is licensed under a Creative Commons Attribution-NonCommercial-NoDerivatives 4.0 International (CC BY-NC-ND 4.0) License. 